\title{
Morphological Features of the Human Placenta and its Free Chorionic Villi in Normal Pregnancies and those with Diabetes and High Blood Pressure. Literature Review
}

\author{
Características Morfológicas de la Placenta Humana y sus Vellosidades Coriales Libres \\ en Gestas Normales y con Diabetes e Hipertensión Arterial. Revisión de la Literatura
}

Ruth Prieto Gómez ; Nicolás Ernesto Ottone ${ }^{2,3}$ \& Homero Bianchi ${ }^{4,5}$

PRIETO, G. R.; OTTONE, N. E. \& BIANCHI, H. Morphological features of the human placenta and its free chorionic villi in normal pregnancies and those with diabetes and high blood pressure. literature review. Int. J. Morphol., 36(4):1183-1192, 2018.

SUMMARY: The most prevalent pathologies during pregnancy, such as hypertension, gestational diabetes mellitus (GDM), and intrauterine growth restriction (IUGR), can determine modifications in macro- and microscopic morphological features of the placenta and its free chorionic villi. In the fetus it may be accompanied by pathological manifestations, with the embryo's future quality of life, and even its viability, at risk. The aim of this work is to perform a review of the morphological alterations that the placenta exhibits in pregnancies with GDM. A search on the topic in the scientific literature and specialized textbooks was carried out. The terms "placenta", "diabetes mellitus gestational" and "gestational diabetes mellitus" were used to define the search. Among the morphological modifications it was found that the placental weight/fetal weight ratio is higher in GDM and is associated mainly with histological changes. The distance between maternal and fetal circulation is increased because of an increase in the chorionic villi on the surface as well as greater thickness of the syncytiotrophoblast basal membrane due to an increased type IV collagen deposition. The stroma between the villi is edematous, which modifies the metabolic and endocrinal function of these placentas. Moreover, the capillary surface is enlarged due to the phenomena of vascular neoformation and a greater penetration of these vessels within the villi. Low oxygen partial pressure $\left(\mathrm{pO}_{2}\right)$ was detected, which would produce a compensatory hyperplasia of terminal chorionic villi. In GDM the placenta undergoes alterations in its formation, structure, and function. According to the review, these alterations are related to an oxygenation deficiency in the fetus and changes in the transplacental transport of nutrients and other alterations, causing fetal overgrowth by increasing their availability in addition to other consequences to the developing fetus. In the case of high blood pressure during pregnancy, this produces accelerated maturation and rapid aging of the chorionic villi, with the risk of inducing a placental abruption. In addition, placental circulation is reduced by a third, decreasing oxygen saturation in the umbilical vessels and placing the health of the fetus at risk.

KEY WORDS: Free chorionic villi; Gestational diabetes mellitus; Hypertension; Morphology; Placenta.

\section{INTRODUCTION}

The placenta is formed as a result of the process of implantation, proliferation, and differentiation of the trophoblast; it is a vital organ for the survival, growth, and development of the embryo and fetus. Structurally the placenta is composed of chorionic villi, which present typical features in a pregnancy in its physiological evolution. Nevertheless, during pregnancy there are prevalent pathologies, such as hypertension and diabetes, that can cause modifications in the macroscopic and microscopic morphological features of the placenta and its free chorionic villi, signifying a risk for fetus, mother, and newborn.

The aim of this work is to perform a review of the morphological features of the human placenta and its free chorionic villi in normal pregnancies and in the presence of high blood pressure and diabetes.

\footnotetext{
${ }^{1}$ Department of Pediatrics and Child Surgery, Medicine School, Universidad de La Frontera, Temuco, Chile.

${ }^{2}$ Research Centre in Dental Sciences (CICO), Dental School, Universidad de La Frontera, Temuco, Chile.

${ }^{3}$ Center of Excelence in Morphologycal and Surgical Sciences, Medicine School, Universidad de La Frontera, Temuco, Chile.

${ }^{4}$ Anatomy Department, Medicine School, University of Buenos Aires, Buenos Aires, Argentina.

${ }^{5}$ IUCS Barcelo Foundation, Buenos Aires, Argentina.

Funded by Universidad de La Frontera, Proyecto DIUFRO No DI16-0074
} 


\section{MATERIAL AND METHOD}

The electronic search was carried out by two independent researchers. The search was done on the MEDLINE and SciELO databases. In MEDLINE the terms "(Chorionic villi) AND hypertension" and "(Chorionic villi) AND diabetes" were used. With respect to the SciELO network, a database of predominantly Latin America journals, with the Spanish terms "placenta hipertensión" and "placenta diabetes", separately. The last electronic search was done on March 21, 2017.

The studies had to provide clear and adequate information on the clinical procedure and the irrigants/ dressings used in regenerative therapy. The search included studies in English, Spanish, French, Portuguese, and Italian. No restriction criteria were applied regarding date of publication. In addition, embryology textbooks were consulted.

Placenta. The human placenta is composed of a fetal part or chorionic plate, and a maternal part or basal plate, each having well-defined features and functions. The chorionic plate is covered by the amnion. The amnion is made up of a single layer of stratified epithelium and amniotic mesenchyme, an avascular connective tissue. The placenta increases $14 \mathrm{~g}$ for every $100 \mathrm{~g}$ that the product increases. According to its weight, it is hypotrophic if less than $300 \mathrm{~g}$ and hypertrophic if more than $700 \mathrm{~g}$. The umbilical cord is inserted in most cases in this part of the placenta in a slightly eccentric position, but there are other types of insertion such as marginal cord insertion, where the cord is attached to the side, or velamentous cord insertion, where the umbilical vessels are separated in the membranes at a certain distance from the placental margin, where they arrive surrounded only by a fold in the amnion. The fetal vessels are unprotected in the placental membranes or umbilical cord (Wharton jelly), and can be bilobed or accessory (Huppertz, 2008; Carlson, 2014). The chorionic plate contains the vessels that continue with those of the umbilical cord. Derived from the two umbilical arteries, the chorionic arteries present a centrifugal distribution pattern in their terminal branches that allow them to supply blood to the villi. The chorionic veins are direct continuations of the veins of the villous trees (stem villi, attached to the plate that reaches the cotyledon) and usually crosses underneath to the chorionic arteries. The chorionic veins give rise to the single umbilical vein (Prieto Gómez et al., 2008).

The basal plate represents the maternal surface of the placenta. It is an artificial surface that emerges from placental separation from the uterine wall during childbirth. The basal plate is a mixture of extravillous fetal trophoblasts and all types of maternal cells of the decidualized uterus, including decidual stromal cells, macrophages, and other immune cells. The basal plate also contains large amounts of extracellular matrix, fibrinoids, and blood clots. It is subdivided into 10 to 40 slightly elevated regions, called cotyledons, and dividing the cotyledons are the septa that trace the lobe borders as irregular pillars. The cotyledons that are visible on the maternal surface of the placenta show a good correspondence to the position of the villous trees derived from the chorionic plate in the intervillous space or blood chamber (Huppertz; Prieto Gómez et al., 2008; Carlson).

Formation of the placenta. The first component of the embryo is the trophoblast, from which the placenta originates. After implantation, the extraembryonic mesoderm appears, located between the trophoblast and the blastocyst cavity. Thus, the trophoblast and the extraembryonic mesoderm will constitute a common structure, the chorion. This is a tissue from which the villi will form that will absorb nutrients and oxygen from the maternal blood to then be transported to what will be the body of the embryo. These villi will first be composed, externally, of syncytiotrophoblast and a cytotrophoblast nucleus, and will receive the number of primary chorionic villi. Then, the extraembryonic mesoderm arises from the nucleus of the primary villi, at which point they become known as secondary villi. Finally, small embryonic blood vessels appear in the extraembryonic mesoderm, and there the villi begin to be called tertiary. With respect to the extension of the villi, they can be defined as "free" when they extend from the villous stem and have no fixation in the cytotrophoblastic shell, floating in the blood chamber bathed in maternal blood. Therefore, the so-called "anchoring villi" are those that reach the cytotrophoblast envelope, and through this reach the decidua, thereby ensuring fixation of the embryo (Sadler, 2004; Huppertz; Prieto Gómez et al., 2011; Roa et al., 2012; Carlson).

The blastocyst is surrounded by trophoblast and thus everything will tend to the formation of chorionic villi; however, the trophoblast from which the implantation began can grow further, causing greater branching of its chorionic villi. This region of the chorion is called the "chorion frondosum", corresponding then to the embryonic portion of the placenta. Therefore, the mature placental barrier will comprise the following components: syncytiotrophoblast, cytotrophoblast, extraembryonic mesoderm, and the endothelial lining of the chorionic vessels (Sadler; Huppertz; Prieto Gómez et al., 2011; Roa et al.; Carlson).

The placental lobules, also called cotyledons, develop from the joining of several chorionic villi. Additionally, these cotyledons are separated by septa that derive from the basal decidua. A placenta will present a total of 20 to 35 cotyledons 
at the end of the pregnancy and each of these will present from 1 to 4 stem villi. Approximately $150 \mathrm{~mL}$ of maternal blood per minute is exchanged between the decidua and the villi, so that the uterine spiral arteries carry maternal blood (oxygenated and with nutrients) to the villi, diffusing the components transported by the blood through the placental barrier and reaching the chorionic vessels, where the return blood will circulate to the embryo. Likewise, the transport of waste and carbon dioxide occurs, but from the chorionic vessels, diffusing to the maternal blood located outside the villi. When the pregnancy is over, the placenta measures approximately $20 \mathrm{~cm}$ in diameter, 2 to $3 \mathrm{~cm}$ thick, $500 \mathrm{~g}$ in weight, and is usually discoid in shape (Sadler; Huppertz; Carlson).

The maturity of the chorionic villi can be evaluated by analyzing the degree of growth or development they reach on the villous tree in relation to the gestational age determined by clinical history or by the weight of the newborn and the placenta. During normal gestation there may be disruptions in the maturation process of the placental villi, accelerating or delaying it. In a normal mature placenta, immature intermediate villi can be found in the central portion of the placentoma or placental lobule. These are villi that continue with their proliferation and represent a type of growth reserve (Castejón \& Molinaro 2004).

In addition, during pregnancy, the chorionic villi can present degenerative changes that, within certain parameters, can be considered normal. However, when the villi begin to appear compromised in large proportion, this can affect the normal development of the fetus, causing structural malformations. The lack of placental development can directly bring about congenital defects, and villous lesions such as trophoblastic necrosis, edema, immaturity, thrombosis, and trophoblast inclusions are also found more frequently in neural tube defects and chromosomal disorders (Castejón \& Molinaro).

Placental Circulation. Maternal and fetal circulation contributes to the development of placental circulation. The two umbilical arteries transport the fetal blood to the placenta, and then they branch off in the chorionic plate, thus creating networks of capillaries in the chorionic villi. The exchange occurs in this sector and then the capillaries become blood vessels, which continue them, enlarging until they form the umbilical vein. The umbilical vein is the one responsible for delivering oxygenated blood to the fetus, and it also contains nutrients and other substances that it receives from the maternal blood, whereas the blood with carbon dioxide and the waste pass through the umbilical arteries. The maternal blood arrives at a type of pool not contained in blood vessels. Between 80 and 100 spiral arteries of the endometrium spill their contents into the intervillous spaces and bathe the villi. This blood arrives at the villi with low pressure, but it manages to reach the villi. The route of the blood follows the villi until arriving at the capillary networks of the fetal vessels, so that the previously mentioned exchange of substances occurs (Sadler; Huppertz; Carlson).

Physiology of the placenta. The functions of the placenta are of great importance for the fetus and the mother. First of all, it ensures the exchange of metabolic and gaseous products between mother and fetus, acting as a barrier between maternal and fetal circulation. Furthermore, this is where the synthesis of substances, such as cholesterol, fatty acids, and glycogen are produced, in addition to an immune function, permitting the transmission of antibodies from mother to fetus. The most noteworthy function of the placenta is the bidirectional mother-fetus/fetus-mother transport through different transport mechanisms, such as simple diffusion, facilitated diffusion and active transport using adenosine triphosphate. Many substances, such as oxygen, water, hormones, electrolytes, drugs, and toxic elements, pass from maternal circulation to the fetal blood (Sadler; Huppertz; Carlson).

Transport of oxygen, water, and electrolytes. It must be considered relevant that the passage of glucose to the fetus by facilitated diffusion is its main source of energy. Free fatty acids also cross the placental barrier and are then esterified in the fetus to form triglycerides. Amino acids can also pass through the placental barrier, thus managing to satisfy the needs of the fetus in terms of protein synthesis.

Transport of hormones and antibodies. Steroid hormones cross the placental barrier freely, whereas thyroid hormones do so very slowly. Protein and peptide hormones cannot cross the placental barrier; antibodies are one exception among elements of a protein nature.

Transport of drugs and toxic substances. Most drugs, toxic substances, and their metabolic products cross the placental barrier.

Endocrine function. In particular, the syncytiotrophoblast is an endocrine tissue that synthesizes important steroid and protein hormones during the greater part of gestation. Hormones produced by the placenta include human chorionic gonadotropin, chorionic somatomammotropin, or placental lactogen, whose action stimulates changes in the metabolism of carbohydrates in the mother in relation to the nutrition of the fetus. For example, inhibiting maternal insulin and leading to an elevation in glycemia levels, thus favoring the passage of glucose to the fetus. Progesterone, estrogens, and relaxin are also produced in the placenta. 
Diabetes. Diabetes mellitus (DM) is a disease characterized by hyperglycemia over a prolonged period. There are three main types: type 1 (DM1), type 2 (DM2), and gestational (GDM). Approximately $10 \%$ of all cases of DM are type 1, which is an autoimmune disease in which there is an absolute insulin deficiency due to the destruction of pancreatic $b$ cells. This destruction can be caused by an autoimmune process (type 1a) or can be idiopathic (type 1b). Most DM1 cases are type $1 \mathrm{~b}$ and it usually manifests before 30 years of age. DM2 affects most people with DM, characterized by a peripheral resistance to the action of insulin and a relative insulin deficiency. Maternal diabetes, which includes patients with DM1, DM2, and GDM, increases the possibility of complications during pregnancy and can cause adverse effects in the fetus. An intrauterine environment with hyperglycemia affects not only the fetus but also the development and function of the placenta (Bastos Aires \& dos Santos, 2015).

In relation to GDM, just as there is an alteration in fetal growth, the placenta is in the same intrauterine environment and therefore also undergoes alterations in its formation, structure, and function. These alterations could be related to an oxygenation deficiency in the fetus and changes in the transplacental transport of nutrients, increasing their availability to the fetus and thus causing fetal overgrowth (Prieto Sanchez, 2013; Bastos Aires \& dos Santos).

Although in patients with GDM there is an increase in both the weight of the placenta and the fetus, the increased weight is more pronounced at the placental than the fetal level, which is why the placental weight:fetal weight ratio is greater in patients with diabetes than in a normal pregnancy. The increase in placental weight in diabetic patients has been associated mainly with changes at the histological level, typically phenomena of hyperproliferation and hypervascularization. In these placentas, the distance between the maternal and fetal circulation is greater because of an increase in the surface between the chorionic villi as well as the greater thickness of the syncytiotrophoblast basal membrane due to an increased type IV collagen deposition. The stroma between the villi is edematous and there is an increase of Hofbauer cells (placental macrophages responsible for the synthesis of leptin, tumor necrosis factor alpha and interleukins), which will modify the metabolic and endocrinal functions of these placentas. Moreover, the capillary surface is enlarged because of the phenomena of vascular neoformation and a greater penetration of these vessels within the villi. This hypervascularization is caused by proangiogenic factors whose synthesis is increased by relative hypoxia (leptin, vascular endothelial growth factor (VEGF), fibroblast growth factor 2), and may serve to compensate for the alteration in the maternal-fetal diffusion of some nutrients, particularly oxygen, which occurs in these patients (Prieto Sanchez).

Ashfaq et al. (2005) determined in their work that the increase in placental weight in diabetic patients can be attributed to compensatory macrosomia and hyperplasia. Macrosomia affects the fetus and the fetal part of the placenta, i.e., the chorionic plate and every type of villi. Because macrosomia affects the fetal part of the placenta, the placental weight, diameter, and central thickness in diabetic mothers increase in comparison with the normal placenta. The placenta in mothers with diabetes is affected by generalized fetal macrosomia observed in GDM. Compensatory hyperplasia of the terminal chorionic villi may be due to the low partial pressure of oxygen $\left(\mathrm{pO}_{2}\right)$ in the blood inside the chorionic villi. This decrease in $\mathrm{pO}_{2}$ is the result of a reduced maternal blood supply flowing into the intervillous space, leading to the development of diabetic endarteritis and resulting in damage to the endothelial cells followed by their proliferation, which can lead to a narrowing of the maternal blood vessel lumens, reducing the uteroplacental circulation. Another cause of low $\mathrm{pO}_{2}$ in the chorionic villus blood may be the excessive thickness of the placental barrier (Kumar et al., 2000). The basal lamina of the chorionic capillaries is part of the placental barrier; therefore, the increase in its thickness will make the placental barrier thicker overall, which can lead to a reduction in the oxygen transport and other nutrients through the barrier. In response to this reduction in $\mathrm{pO}_{2}$, the terminal villi exhibit a hyperplasia that may be partially responsible for the increased placental weight in the diabetic group (Salvatore, 1968; Ashfaq et al.).

According to Maly et al. (2005), in the case of maternal diabetes, the structure of the placental villi was focally edematous and immature with an increase in mature and immature intermediate villi and a relatively reduced number of terminal villi with the formation of syncytial knots.

The most common placental findings in the environment of previous GDM are the increase in the immaturity of the villi and the increase in angiogenesis (Huynh et al., 2015). Angiogenesis, defined as the process of forming new blood vessels that arise from preexisting ones, is essential to fetal growth and normal placental development. Generally, there are two phases in angiogenesis: branching angiogenesis with the formation of looped capillaries, and nonbranching angiogenesis with the formation of longer capillaries (Mayhew, 2002a; Kaufmann et al., 2004; Roescher et al., 2011; Blackburn, 2013). In a study done by Mayhew (2002b), an increase in nonbranching angiogenesis was reported with no change in the caliber of 
the cross section or the shape of the capillaries in comparison with the controls in placentas affected by maternal DM1 despite finding adequate levels of glycosylated hemoglobin. By contrast, an increase in branching angiogenesis along with hypovascularized and hypervascularized terminal villi, and an increase in the number of superficial capillaries in the terminal villi were observed in placentas affected by maternal DM1 with good glucose control (Teasdale, 1981; Asmussen, 1982; Jirkovska, 1991; Jirkovska et al., 2002; Jirkovska et al., 2008). These findings suggest that the placentas of pregnancies complicated by dysglycemia can show increases in branching and nonbranching angiogenesis. Additionally, the increased incidence of immature villi is commonly seen in placentas affected by diabetes (Evers et al., 2003; Daskalakis et al., 2008; Madazli et al., 2008). This placental abnormality, which has been independently associated with a higher risk of perinatal mortality, can serve as a link between maternal diabetes and a greater risk of fetal intrauterine death (Higgins et al., 2011; Tennant et al., 2014).

Salge et al. (2012) sought to identify the macroscopic changes of the placenta associated with the clinical conditions in women with or without diabetes and their newborns. They reported findings consistent with infarction, hematoma, calcification, and fibrin deposits on the maternal and fetal placental surfaces of women with DM. The women with GDM and the newborns presented more calcium deposits on the maternal placental surface than those with DM1 and DM2.

Vascular endothelial cadherin and b-catenin play a key role in the establishment and maintenance of the integrity of the endothelial monolayer, the regulation of the vascular barrier function and the beginning of angiogenesis, with the cadherin-catenin complex being reduced in the placentas of patients with DM1. In this sense, Baumüller et al. (2015) found through immunohistochemical studies that the placental tissue in DM1, DM2, and GDM presents normal energy levels of vascular endothelial cadherin and b-catenin in the fetoplacental vessels as long as the patient has not been treated with insulin. On this basis, they suggested that the therapeutic intervention operation with insulin in pregnancies complicated by DM could have potentially harmful effects on the placental morphology, with a reduction in vascular endothelial cadherin and b-catenin in some portions of the chorionic villi.

In placentas of noncomplicated pregnancies, the Hofbauer cells disappear or become scarce after the fourth to fifth month of gestation. Nevertheless, it has been revealed through immunohistochemistry that a high percentage of stromal cells belong to the Hofbauer cells. Grigoriadis et al. (2013) investigated the changes in the morphology and density of the Hofbauer cells in placentas of normal and pathological pregnancies.

In the control cases examined by hematoxylin and eosin staining, Hofbauer cells were found in $37.5 \%$ of the cases, whereas by immunohistochemistry the cells were found in $87.5 \%$ of the cases. In the cases of GDM, positive immunoreaction was observed in $70 \%$ of the cases. These authors established that Hofbauer cells are present in the placental villi during pregnancy, but with a progressive reduction in density. The most specific marker for their detection seems to be A1-antichymotrypsin. They did not find any mitotic activity of the Hofbauer cells, because the Ki-67 marker for cellular multiplication was negative in all the specimens examined.

Yavuz et al. (2015) studied VEGF and CD68 expression immunohistochemically in the placenta of mothers with GDM. They verified that the expression of VEGF and its receptors increased in the placental chorionic villi mainly in GDM, whereas in the nondiabetic villi a weak VEGF expression was detected. In all the placental tissues of the GDM group, immunohistochemical staining revealed the presence of CD68. For their part, the trophoblast and Hofbauer cells were dyed with CD68. The Hofbauer cells were observed generally near the vascular zone in the villous stroma, with CD68 also being detected around the vein simultaneously with the presence of inflammatory cells. In addition, the Hofbauer cells expanded into the endoplasmic reticulum, the mitochondria were swollen, and the nucleus was heterochromatic. A focal increase was observed in the thickness of the endothelial basal membrane in most of the placentas. A general increase in the collagen component of the villous stroma was observed.

Shchegolev et al. (2013) compared the expression of the placental VEGF and its receptors (VEGFR-1, VEGFR-2, and VEGFR-3) at the immunohistochemical level in GDM and DM1. From these studies they identified an increase in the expression of VEGF and its receptors in the terminal villi of the placenta, mainly in patients with DM1. These changes they found in the immunophenotype of the terminal villi suggest that the placenta is damaged and, consequently, this can lead to disorders in intrauterine growth restriction and other diseases in the newborn.

Srinivasan et al. (2014) studied the effects of hypoxia on the vascularization of the placental terminal villi. They identified chorangiosis as the most frequent lesion, whereas chorangioma was found less frequently. 
Hypertension. Chronic high blood pressure during pregnancy, alone or in association with preeclampsia, is a clinical complication related to a high risk of maternal and perinatal morbidity. Considering that many women experience pregnancy after the third decade of life, we can say that the presence of chronic high blood pressure during pregnancy is an increasingly frequent phenomenon (Voto, 2008; MINSAL, 2014).

Uteroplacental circulation in pregnant women with chronic high blood pressure can be affected to varying degrees, depending on the changes in microcirculation, mediated by functional disorders such as preeclampsia or as a result of chronic vascular lesions, resulting in a significant drop in tissue perfusion. Consequently, placental ischemia and infarction will occur, determining a functional fault and the ensuing difficulties to satisfy the needs for adequate fetal development when there is a restricted supply of oxygen and nutrients, which can facilitate the occurrence of acute events such as placental abruption as well as long-term effects (Voto). George et al. (2014) also indicated that a result of placental ischemia is modification of the gene expression, causing a significant increase (2500), but in the great majority, only 22 showed a change greater than or equal to $50 \%$ in expression over the control levels. Additionally, in the same work George et al. indicated that of the 22 genes, only one, osteoglycin, underwent downregulation, suggesting an overall increasein gene expression.

The chorionic villi in pregnant women with hypertensive disorders undergo a process of accelerated maturation; rapid aging can give rise to early apoptosis or necrosis of the trophoblast that would cause a separation of the anchoring villi, fixed on the basal plate; as a result, placental abruption would be imminent. During normal gestation, however, there may also be disturbances in the maturation process of the chorionic villi. Growth of the villi can be accelerated or delayed. In a normal mature placenta the immature intermediate villi are located in the central portion of the placentoma or placental lobule, they are villi that are still proliferating and represent a type of growth in reserve (Bernirschke \& Kaufmann, 2000). The prevalence of immature intermediate villi and villi with vessels near the center of the stromal region as well as the presence of increased cytotrophoblasts or those in proliferation and the nonexistence of syncytial bridges in the intervillous space have been considered determining factors of immaturity of the villi during the first trimester of a normal pregnancy.

Maly et al. determined that macroscopic and microscopic tests on the placentas of pregnancies with preeclampsia showed ischemic changes such as the formation of prominent syncytial knots and areas of marked angiogenic branching. Fibrinoid necrosis and intramural lipid deposition were found in the walls of the uterine vessels (acute atherosis) in many of the placentas, and macroscopic examination revealed the presence of infarcts in six placentas, which affected less than $10 \%$ of the placental volume in each case.

In the case of maternal hypertension, Ashfaq et al. established that atherosclerosis affects the blood vessels in the uterus, narrowing their lumens, which leads to a reduced blood flow in the intervillous space (Salvatore). Apoptosis, both a physiological and pathological condition of cell death, increases in hypoxic conditions. In response to this hypoxia, the villi exhibited compensatory hyperplasia but with greater elimination of parenchymal cells by apoptosis. These parenchymatous cells were later replaced by fibrous tissue. These two processes, i.e., apoptosis and compensatory hyperplasia, occur in parallel and balance each other in such a way that no significant difference is found in the placental weight, diameter, or central thickness in the hypertensive group compared to the normal placenta (Karlsson et al., 1982).

Hypertension and inflammation are both frequently associated with more cases of DM2 than DM1 (Jawerbaum \& Gonzalez, 2006; Shams et al., 2012). Beauharnais et al. (2012) reported in their study that in the placentas of pregnancies complicated by DM2 there was a significant increase in placental infarctions compared to patients with DM1. Soma et al. (1982) described this vascular anomaly in studies into hypertension during pregnancy.

In studies by Majumdar et al. (2005), Janthanaphan et al. (2006), and Artico et al. (2009) on placentas in pregnant women with preeclampsia and prehypertension, a reduction in placental volumes and weights was found as well as an increase in the areas of infarction and hematomas. Histologically, these infarctions appeared as necrotic villous tissue; from the macroscopic point of view, they correspond to triangular areas, of variable dimensions, related to the basal plate and located mainly in the periphery of the placental disc. Infarction, although not a lesion specific to preeclampsia given that it is also found in full-term pregnancies without complications, in these cases appears more frequently and in the peripheral region.

In the work by Janthanaphan et al., on placentas in pregnant women with different types of hypertension, they identified macroscopic infarcts in $61 \%$ of the cases, affecting an approximate area of $5 \%$ of the placental tissue. For their part, Artico et al. observed infarctions in $51.2 \%$ of the cases, of which $9.3 \%$ were central and $25.6 \%$ peripheral, and in $16.3 \%$ the infarction was central and peripheral. 
With respect to the obstructive lesions of the decidual arteries that occur in hypertensive patients, there are authors who concur about the need to separate the cases of pregnant women with preeclampsia and those who present with previous hypertension (Bernirschke \& Kaufmann; Artico et al.). However, regardless of the type of hypertension, these obstructive lesions have been associated with a reduced blood flow dependent on a generalized arteriolar spasm, continuing to the development of a hypoxic state. The oxygen deficiency shows that the placental circulation in the hypertensive patient is reduced by a third and confirms that oxygen saturation in the arteries and umbilical veins of the fetus of pregnant women with preeclampsia is reduced. The partial or total occlusion of the placental vessels plays an important role in how the health of the fetus is affected.

Although essential hypertension causes delayed systemic morphological lesions, it also induces the proliferation of connective tissue in the walls of the basal arteries, and determines an excessive proliferation of fibrous tissue and both intimal and medial smooth muscle, promoting stenosis and occlusion of these arteries. Huppertz demonstrated the acute development of fibrinoid necrosis and acute atherosis in patients with preeclampsia and eclampsia. Benirschke \& Kaufmann and Janthanaphan et al. reported that atherosis is a pathology characterized by several microscopic changes that may or may not be associated: partial vascular obliteration, thickening of the vascular wall, leukocyte infiltration in the vascular wall, granulomatous reaction, presence of vascular hyalinization, substitution of the intima by macrophages, and reduction in vessel lumens. Artico et al. observed the appearance of atherosis, with partial obliteration of the vessel lumen in $44.2 \%$, thickening of the layers of the arterial wall in $44.2 \%$, and the presence of hyalinized vessels in $27.9 \%$ of the cases.

Artico et al. observed in the placentas of pregnant women with hypertension characteristic lesions in the arterioles of the villous stems, represented by hyperplasia of the muscular layer and great thickening of the subendothelial connective tissue, with proliferation and fibrocyte invasion by leukocytes, which determines progressive obstruction of the vessel lumens. Sclerosis predominates in such lesions, which affects the villous trunks and the villi. Therefore, atherosclerosis is the distinguishing seal of hypertensive disease in pregnancy, which is why it is thought that the main changes observed in the placenta are the result of changes in the spiral arteries of the placenta.

Tenney \& Parker (1940) published a study in which they identified hypertrophy of the syncytiotrophoblast as a typical lesion of preeclampsia. The lesion is characterized by a large formation of syncytial nuclei and numerous clusters of nuclei in the villi that determined premature aging of the placenta. Although some of these histological features could be found in the placentas of normal pregnancies, they presented with greater prominence in placentas related to hypertensive disease, even in the initial stages of hypertension. The changes described by Tenney \& Parker can be seen in significant numbers after gestational week 32 , being present at full term in approximately one-third of the villi. Although there is controversy about their meaning, electron microscope studies have revealed that these aged cells, grouped like the younger cells and derived from the cytotrophoblast, remain scattered on the surface of the villi.

Mesquita et al. (2003) and Correa et al. (2008) indicated that the increasing number of syncytial nuclei, associated with necrosis of the villi, fibrin deposits, and calcification foci, would be part of the physiological aging process of the placenta, causing an increase during hypertensive syndrome. Therefore, this phenomenon is characterized by the increase in the features established by Tenney \& Parker, resulting in a process of uteroplacental hypoxia, as in the cases of eclampsia, or a process of fetoplacental hypoxia, as happens in the cases of thrombosis of the fetal arteries. There is a greater association of the development of infarcts, blood clots, hematomas, atherosis, and a lower placental weight and volume with hypertensive syndromes (Artico et al.).

Prins et al. (2012) established in their study the participation of the maternal immune system in remodeling the uterine spiral artery, invasion of the trophoblast, and the simultaneous acceptance of the semiallogenic fetus during pregnancy. Prior to deregulation of the maternal immune system, a product of maternal hypertension, in first-trimester decidua there is a greater expression of interleukin 6 and messenger ribonucleic acid of macrophages with fewer regulatory macrophages. The authors then detected a lower expression of Gata3 (Th2) messenger ribonucleic acid in decidua of the pregnancies with subsequent intrauterine growth restriction. Thus, they confirmed the appearance of adverse results in thirdtrimester placentas associated with immune disorders resulting from high blood pressure during pregnancy.

Wang et al. (2012) detected a maternal autoantibody circulating, the autoantibody agonist of angiotensin II receptor type 1 , which stimulates the deposition of complement $\mathrm{C} 3$ in the placentas and kidneys of pregnant mice by activating angiotensin II receptor type 1 . Similarly, in humans, it was demonstrated that the deposition of $\mathrm{C} 3$ 
is significantly higher in the placentas of preeclamptic patients than in normotensive controls. The angiotensin II receptor type 1 mediated by the activation of an agonist autoantibody contributes to the elevation of $\mathrm{C} 3$ and the signaling receptor of complement $\mathrm{C} 3 \mathrm{a}$, a key mechanism in the pathogenesis of preeclampsia.

Kalkanli et al. (2013) associated preeclampsia, proteinuria, and edema with hypertension during pregnancy. Using histopathology they found an increase in hyperplasia and hyalinization in syncytial nodules and stromal cells of the placenta. They also detected a positive reaction of CD34 in immunohistochemical studies of the chorionic villi, placenta, and hematopoietic stem cells. At ultrastructural level they detected dilation of the endoplasmic reticulum, mitochondrial degeneration in the endothelial cells, and edema of the capillary vessels.

Yamaleyeva et al. (2015) studied the role of endogenous apelin in pregnancy. Although it was established that its action is not as yet well known, due to the expression of multiple forms of the peptide, the study authors managed to establish by radioimmunoassay its expression in the chorionic villi of pregnant women with preeclampsia and normal pregnant women at 36 to 38 weeks of gestation. They established the expression of a smaller amount of apelin in human placental chorionic villi in patients with preeclampsia, with [Pyr1]-apelin-13 being the predominant form of endogenous apelin in the chorionic villi of normal pregnancies and with preeclampsia. The potential mechanism of lower apelin expression in the chorionic villi of pregnancies with preeclampsia may imply a negative regulation of apelin by angiotensin II.

\section{CONCLUSION}

In GDM the placenta undergoes alterations in its formation, structure, and function. According to the review, these alterations are related to an oxygenation deficiency in the fetus, changes in the transplacental transport of nutrients and other alterations that cause fetal overgrowth by increasing their availability, and other consequences to the developing fetus.

High blood pressure during pregnancy produces accelerated maturation and rapid aging of the chorionic villi with the risk of inducing a placental abruption. In addition, placental circulation is reduced by a third, decreasing oxygen saturation in the umbilical vessels and placing the health of the fetus at risk. The two pathologies are frequently associated in the same pregnancy.
PRIETO, G. R.; OTTONE, N. E. \& BIANCHI, HOMERO, H. Características morfológicas de la placenta humana y sus vellosidades coriales libres en gestas normales y con diabetes e hipertensión arterial. revisión de la literatura. Int. J. Morphol., 36(4):1183-1192, 2018.

RESUMEN: Las patologías de la gestación más prevalentes, como hipertensión, diabetes mellitus gestacional (DMG) y restricción del crecimiento uterino, pueden determinar modificaciones en las características morfológicas macro y microscópicas de la placenta y sus vellosidades coriales libres,y en el feto se puede acompañar de manifestaciones patológicas, con riesgo para su calidad de vida futura, e incluso su viabilidad. El objetivo de este trabajo consiste en realizar una revisión acerca de las alteraciones morfológicas que presenta la placenta en gestaciones con DMG. Se llevó a cabo una búsqueda sobre la temática en literatura científica y libros de texto especializados. Se utilizaron los términos "placenta", "diabetes mellitus gestacional" y "gestational diabetes mellitus" para orientar la búsqueda. Entre las modificaciones morfológicas se encontró que la relación peso placentario/peso fetal está aumentado en la DMG y se asocia principalmente a cambios histológicos. La distancia entre la circulación materna y la fetal está aumentada debido a un aumento de la superficie entre las vellosidades coriales, así como al mayor grosor de la membrana basal del sincitiotrofoblasto por un depósito elevado de colágeno tipo IV. El estroma entre las vellosidades se encuentra edematoso lo que va a modificar la función metabólica y endocrina de estas placentas. También hay aumento de la superficie capilar por fenómenos de neoformación vascular y una mayor penetración de estos vasos dentro de las vellosidades. Se detectó baja presión parcial de oxígeno $\left(\mathrm{pO}_{2}\right)$, que produciría una hiperplasia compensatoria de vellosidades coriónicas terminales. En la DMG la placenta experimenta alteraciones en su formación, estructura y función. Según lo revisado, estas alteraciones están relacionadas con déficit en la oxigenación del feto, cambios en el transporte transplacentario de los nutrientes y otras alteraciones, ocasionando sobrecrecimiento fetal por aumento de su disponibilidad, entre otras consecuencias al feto en desarrollo. Y en el caso de la hipertensión arterial durante la gestación produce una maduración acelerada y envejecimiento rápido de las vellosidades coriales, con el riesgo de inducir un desprendimiento prematuro de placenta. Además se reduce la circulación placentaria en un tercio, disminuyendo la saturación de oxígeno en los vasos umbilicales del, poniendo en riesgo la salud del feto.

PALABRAS CLAVE: Placenta; Vellosidades coriales libres; Diabetes mellitus gestacional; Hipertensión; Morfología.

\section{REFERENCES}

Artico, L. G.; Madi, J. M.; Godoy, A. E. G.; Coelho, C. P.; Rombaldi, R. L. \& Artico, G. R. Alterações histopatológicas em placentas humanas relacionadas às síndromes hipertensivas. Rev. Bras. Ginecol. Obstet., 31(1):10-6, 2009.

Ashfaq, M.; Janjua, M. Z. \& Channa, M. A. Effect of gestational diabetes and maternal hypertension on gross morphology of placenta. J. Ayub. Med. Coll. Abbottabad, 17(1):44-7, 2005. 
Asmussen, I. Ultrastructure of the villi and fetal capillaries of the placentas delivered by non-smoking diabetic women (White group D). Acta Pathol. Microbiol. Immunol. Scand. A, 90(2):95-101, 1982.

Bastos Aires, M. \& dos Santos, A. C. V. Effects of maternal diabetes on trophoblast cells. World J. Diabetes, 6(2):338-44, 2015.

Baumüller, S.; Lehnen, H.; Schmitz, J.; Fimmers, R. \& Müller, A. M. The impact of insulin treatment on the expression of vascular endothelial cadherin and Beta-catenin in human fetoplacental vessels. Pediatr. Dev. Pathol., 18(1):17-23, 2015.

Beauharnais, C. C.; Roberts, D. J. \& Wexler, D. J. High rate of placental infarcts in type2 compared with type 1 diabetes. J. Clin. Endocrinol. Metab., 97(7):E1160-4, 2012.

Bernirschke, K. \& Kaufmann, P. Pathology of the Human Placenta. $4^{\text {th }}$ ed. Nueva York, Springer-Verlag, 2000.

Blackburn, S. Prenatal Period and Placental Physiology. Maternal, Fetal \& Neonatal Physiology. $4^{\text {th }}$ ed. Maryland Heights, Saunders, 2013. pp.79-85.

Carlson, B. M. Embriología Humana y Biología del Desarrollo. $5^{\text {th }}$ ed. Ann Arbour, Elsevier, 2014.

Castejón, O. C. \& Molinaro, M. P. Madurez de las vellosidades coriales y su relación con desordenes hipertensivos en casos de desprendimiento prematuro grave de placenta normoinserta. Rev. Fac. Cienc. Salud Univ. Carabobo, 8(3):17-26, 2004.

Correa, R. R.; Gilio, D. B.; Cavellani, C. L.; Paschoini, M. C.; Oliveira, F. A.; Peres, L. C.; Reis, M. A.; Teixeira, V. P. \& Castro, E. C. Placental morphometrical and histopathology changes in the different clinical presentations of hypertensive syndromes in pregnancy. Arch. Gynecol. Obstet., 277(3):201-6,2008.

Daskalakis, G.; Marinopoulos, S.; Krielesi, V.; Papapanagiotou, A.; Papantoniou, N.; Mesogitis, S. \& Antsaklis, A. Placental pathology in women with gestational diabetes. Acta Obstet. Gynecol. Scand., 87(4):403-7, 2008.

Evers, I. M.; Nikkels, P. G.; Sikkema, J. M. \& Visser, G. H. Placental pathology in women with type 1 diabetes and in a control group with normal and large for gestational age infants. Placenta, 24(8-9):819-25, 2003.

George, E. M.; Garrett, M. R. \& Granger, J. P. Placental ischemia induces changes in gene expression in chorionic tissue. Mamm. Genome, 25(56):253-61, 2014

Grigoriadis, C.; Tympa, A.; Creatsa, M.; Bakas, P.; Liapis, A.; Kondi-Pafiti, A. \& Creatsas, G. Hofbauer cells morphology and density in placentas from normal and pathological gestations. Rev. Bras. Ginecol. Obstet., 35(9):407-12, 2013.

Higgins, M.; McAuliffe, F. M. \& Mooney, E. E. Clinical associations with a placental diagnosis of delayed villous maturation: a retrospective study. Pediatr. Dev. Pathol., 14(4):273-9, 2011.

Huppertz, B. The anatomy of the normal placenta. J. Clin. Pathol., 61(12):1296-302, 2008.

Huynh, J.; Dawson, D.; Roberts, D. \& Bentley-Lewis, R. A systematic review of placental pathology in maternal diabetes mellitus. Placenta, 36(2):101-14, 2015.

Janthanaphan, M.; Kor-Anantakul, O. \& Geater, A. Placental weight and its ratio to birth weight in normal pregnancy at Songkhlanagarind Hospital. J. Med. Assoc. Thai., 89(2):130-7, 2006.

Jawerbaum, A. \& Gonzalez, E. Diabetic pregnancies: the challenge of developing in a pro-inflammatory environment. Curr. Med. Chem., 13(18):2127-38, 2006.

Jirkovska, M. Comparison of the thickness of the capillary basement membrane of the human placenta under normal conditions and in type 1 diabetes. Funct. Dev. Morphol., 1(3):9-16, 1991.

Jirkovska, M.; Janacek, J.; Kalab, J. \& Kubínova, L. Three-dimensional arrangement of the capillary bed and its relationship to microrheology in the terminal villi of normal term placenta. Placenta, 29(10):892-7, 2008.

Jirkovska, M.; Kubínova, L.; Janacek, J.; Moravcova, M.; Krejcí, V. \& Karen, P. Topological properties and spatial organization of villous capillaries in normal and diabetic placentas. J. Vasc. Res., 39(3):26878, 2002.

Kalkanli, S.; Deveci, E.; Sak, M. E.; Evsen, M. S.; Baran, O.; Ozekinci, S. \& Yavuz, D. CD34 expression of chorionic villous in pre-eclamptic placenta: an immunohistochemical and ultrastructural study. Clin. Exp. Obstet. Gynecol., 40(3):425-8, 2013.

Karlsson, K.; Ljunglslad, U. L. F. \& Lundgren, Y. Blood flow of reproductive system in renal hypertensive rats during pregnancy. Am. J. Obstet. Gynec., 142:1039-44, 1982.

Kaufmann, P.; Mayhew, T. M. \& Charnock-Jones, D. S. Aspects of human fetoplacental vasculogenesis and angiogenesis. II. Changes during normal pregnancy. Placenta, 25(2e3):114-26, 2004.

Kumar, V.; Cotran, S. \& Robin, S. L. Basic Pathology. $6^{\text {th }}$ ed. Pennsylvania, W. B. Saunders, 2000.

Madazli, R.; Tuten, A.; Calay, Z.; Uzun, H.; Uludag, S. \& Ocak, V. The incidence of placental abnormalities, maternal and cord plasma malondialdehyde and vascular endothelial growth factor levels in women with gestational diabetes mellitus and nondiabetic controls. Gynecol. Obstet. Invest., 65(4):227-32, 2008.

Majumdar, S.; Dasgupta, H.; Bhattacharya, K. \& Bhattacharya, A. A study of placenta in normal and hypertensive pregnancies. J. Anat. Soc. India, 54(2):1-9, 2005.

Maly, A.; Goshen, G.; Sela, J.; Pinelis, A.; Stark, M. \& Maly, B. Histomorphometric study of placental villi vascular volume in toxemia and diabetes. Hum. Pathol., 36(10):1074-9, 2005.

Mayhew, T. M. Enhanced fetoplacental angiogenesis in pre-gestational diabetes mellitus: the extra growth is exclusively longitudinal and not accompanied by microvascular remodelling. Diabetologia, 45(10):14349, 2002b.

Mayhew, T. M. Fetoplacental angiogenesis during gestation is biphasic, longitudinal and occurs by proliferation and remodelling of vascular endothelial cells. Placenta, 23(10):742-50, 2002a.

Mesquita, M. R. S.; Sass, N.; Stavalle, J. N. \& Camano, L. O leito placentário no descolamento prematuro da placenta. Rev. Bras. Ginecol. Obstet., 25(8):585-91, 2003.

Ministerio de Salud (MINSAL). Guía Perinatal. Programa Nacional Salud de la Mujer. Santiago de Chile, Ministerio de Salud, Gobierno de Chile, 2014.

Prieto Gómez, R.; Matamala, F. \& Rojas, M. Características morfológicas y morfométricas de la placenta de término, en recién nacidos pequeños para la edad gestacional (PEG) en la ciudad de Temuco-Chile. Int. J. Morphol., 26(3):615-21, 2008.

Prieto Gómez, R.; Smok, C. \& Rojas, M. Experiencias de blog: Placenta comparada. Int. J. Morphol., 29(2):432-5, 2011.

Prieto Sanchez, T. Influencia de la Diabetes Mellitus Gestacional en Parámetros Antropométricos y Bioquímicos Materno-Fetales y en la Transferencia Placentaria de Ácidos Grasos. Tesis doctoral. Murcia, Universidad de Murcia, 2013.

Prins, J. R.; Faas, M. M.; Melgert, B. N.; Huitema, S.; Timmer, A.; Hylkema, M. N. \& Erwich, J. J. Altered expression of immune-associated genes in first-trimester human decidua of pregnancies later complicated with hypertension or foetal growth restriction. Placenta, 33(5):453-5, 2012.

Roa, I.; Smok, C. \& Prieto Gómez, R. Placenta: Anatomía e histología comparada. Int. J. Morphol., 30(4):1490-6, 2012.

Roescher, A. M.; Hitzert, M. M.; Timmer, A.; Verhagen, E. A.; Erwich, J. J. \& Bos, A. F. Placental pathology is associated with illness severity in preterm infants in the first twenty-four hours after birth. Early Hum. Dev., 87(4):315-9, 2011.

Sadler, T. W. Langman: Embriología Médica con Orientación Clínica. $9^{\text {th }}$ ed. Madrid, Editorial Médica Panamericana, 2004.

Salge, A. K. M.; Rocha, K. M. N.; Xavier, R. M.; Ramalho, W. S.; Rocha, E. L.; Guimarães, J. V.; Silva, R. C. R.; Siqueira, K. M.; Abdalla, D. R.; Michelin, M. A. \& Murta, E. F. F. C. Macroscopic placental changes associated with fetal and maternal events in diabetes mellitus. Clinics, 67(10):1203-8, 2012.

Salvatore, A. C. The placenta in acute toxemia. Am. J. Obstet. Gynecol., 102(3):347-53, 1968. 
Shams, F.; Rafique, M.; Samoo, N. A. \& Irfan, R. Fibrinoid necrosis and hyalinization observed in normal, diabetic and hypertensive placentae. J. Coll. Physicians Surg. Pak., 22(12):769-72, 2012.

Shchegolev, A. I.; Dubova, E. A.; Pavlov, K. A.; Esayan, R. M.; Shestakova, M. V. \& Sukhikh, G. T. Comparative immunohistochemical evaluation of vascular endothelial growth factor and its receptors in the placental villi in gestational diabetes mellitus and type 1 diabetes. Arkh. Patol., 75(5):13-8, 2013

Soma, H.; Yoshida, K.; Mukaida, T. \& Tabuchi, Y. Morphologic changes in the hypertensive placenta. Contrib. Gynecol. Obstet., 9:58-75, 1982.

Srinivasan, A. P.; Omprakash, B. O. \& Lavanya, K.; Subbulakshmi Murugesan, P. \& Kandaswamy, S. A prospective study of villous capillary lesions in complicated pregnancies. J. Pregnancy, 2014:193925, 2014

Teasdale, F. Histomorphometry of the placenta of the diabetic women: Class A diabetes mellitus. Placenta; 2(3):241-51, 1981.

Tennant, P. W.; Glinianaia, S. V.; Bilous, R. W.; Rankin, J. \& Bell, R. Preexisting diabetes, maternal glycated haemoglobin, and the risks of fetal and infant death: a population-based study. Diabetologia, 57(2):28594, 2014.

Tenney, B. \& Parker, F. The placenta in toxemia of pregnancy. Am. J. Obstet. Gynecol., 39:1000-5, 1940.

Voto, L. Hipertensión en el Embarazo. En: de la Serna, F. \& Cingolani, H. (Eds.). Tratado de Cardiología de la Federación Argentina de Cardiología. Buenos Aires, Federación Argentina de Cardiología, 2008. Disponible en: http://www.fac.org.ar/1/publicaciones/libros/tratfac/ hta_01/hta_embarazo.pdf

Wang, W.; Irani, R. A.; Zhang, Y.; Ramin, S. M.; Blackwell, S. C.; Tao, L.; Kellems, R. E. \& Xia, Y. Autoantibody-mediated complement C3a receptor activation contributes to the pathogenesis of preeclampsia. Hypertension, 60(3):712-21, 2012.

Yamaleyeva, L. M.; Chappell, M. C.; Brosnihan, K. B.; Anton, L.; Caudell, D. L.; Shi, S.; McGee, C.; Pirro, N.; Gallagher, P. E.; Taylor, R. N.; Merrill, D. C. \& Mertz, H. L. Downregulation of apelin in the human placental chorionic villi from preeclamptic pregnancies. Am. J. Physiol. Endocrinol. Metab., 309(10):E852-60, 2015.

Yavuz, D.; Balsak, D.; Ekinci, C.; Tahaoglu, A. E.; Togrul, C.; Görük, N.; Aktas, A. \& Karaman, E. Expression of VEGF and CD68 in the placenta of gestational diabetic mothers (immunohistochemistry and ultrastructural study). Int. J. Morphol., 33(2):522-6, 2015.

\author{
Corresponding Author: \\ Ruth Prieto Gómez \\ Department of Pediatrics and Child Surgery \\ Medicine School \\ Universidad de La Frontera \\ Temuco \\ CHILE
}

Email: ruth.prieto@ufrontera.cl

Received: 28-03-2018

Accepted: 20-07-2018 